\title{
Paroxysmal Nonepileptic Spells in Adolescence
}

\author{
Erin Willis ${ }^{1}$ Debopam Samanta ${ }^{1}$ \\ ${ }^{1}$ Department of Pediatrics, Section of Child Neurology, University of \\ Arkansas for Medical Sciences, Little Rock, Arkansas, United States \\ J Pediatr Epilepsy 2015;4:118-122.
}

\begin{abstract}
Address for correspondence Erin Willis, MD, Section of Child Neurology, University of Arkansas for Medical Sciences, 1 Children's Way, Slot 512-15, Little Rock, AR 72205, United States

(e-mail: williserinw@uams.edu).
\end{abstract}
Abstract
Keywords
- paroxysmal nonepileptic
- spells
- psychogenic seizures

Paroxysmal nonepileptic spells refer to events that clinically can resemble epileptic seizures but are not caused by abnormal epileptiform activity in the brain. These spells can often be difficult to diagnose owing to clinical similarities, but a correct diagnosis is needed to prevent unnecessary treatment with antiepileptic drugs. We review the most common diagnoses in adolescents that can be mistaken for epilepsy, including migraine, syncope, movement disorders, sleep disorders, and psychologic disorders.

\section{Introduction}

Paroxysmal nonepileptic spells are often difficult to diagnose in pediatric patients owing to overlapping clinical features with epileptic seizures. A diagnosis of epilepsy is typically associated with pharmacologic and social sequelae, and an incorrect diagnosis can create an unnecessary burden highlighting the need for proper identification of paroxysmal nonepileptic spells. The adolescent population can present a further unique challenge compared with younger patients, and the common etiologies of nonepileptic events can often differ. These events can be seen in both psychiatric and nonpsychiatric conditions with the most common paroxysmal spell with a psychiatric basis being psychogenic nonepileptic seizures (PNES). ${ }^{1}$ The objective of this review is to identify common mimickers of epilepsy in adolescents, including migraine, syncope, movement disorders, sleep disorders, and psychologic disorders.

\section{Migraine}

Children and adolescents can have a wide variety of presenting symptoms with headaches, which makes the initial diagnosis difficult. In addition, migraine equivalents involving recurrent intermittent episodes without a clinical headache can be seen in $70 \%$ of children and adolescents with headaches. ${ }^{2}$ Given similar neurologic and autonomic features of both migraines and epilepsy, it is important to understand clinical features that are more indicative of a certain diagnosis. Furthermore, an overlap can be seen, as postictal headaches are often reported in patients with epilepsy. $^{3}$

A common form of headache in adolescents is migraine and at times symptomatology can resemble characteristics of seizures. For example, visual auras can be present in both migraines and occipital seizures; however, distinguishing features include an aura of longer duration in migraine that can propagate over several minutes and tend to spread over the visual field. Patients often describe a serrated or zigzag appearance to the visual disturbance. ${ }^{4}$ This is in contrast to epileptic occipital auras, which tend to be stereotypical and brief, often with colored circular patterns. ${ }^{5}$ Auras associated with migraine are also typically followed by a headache with typical migrainous features. In similar fashion, migrainous somatosensory or auditory auras tend to last for longer periods with greater simplicity compared with brief stereotypical symptoms that are more complex in focal epilepsy. Atypical migraines, such as basilar-type migraine or acute confusional migraine, can cause prolonged confusion that can mimic nonconvulsive status epilepticus or perhaps a prolonged postictal state. Basilar-type migraine can also trigger vasovagal syncope or possibly even convulsions. ${ }^{6}$ Acute confusional migraine occurs more commonly in children and adolescents with the majority of patients being younger than 21 years. ${ }^{7}$ Given the clinical similarities, it has been suggested that acute confusional migraine might be a variant of transient global amnesia seen more commonly in adults. ${ }^{8}$ The level of associated dysfunction can vary from mild behavioral changes to even coma. In addition to confusion, language deficits can develop and last for hours, making the differential received

December 14, 2014

accepted

January 11, 2015

published online

August 21, 2015
Issue Theme Adolescent Epilepsies; Guest Editors: Gregory B. Sharp, MD, and Debopam Samanta, MD
Copyright (c) 2015 by Georg Thieme Verlag KG, Stuttgart . New York
DOI http://dx.doi.org/ 10.1055/s-0035-1556735. ISSN 2146-457X. 
concerning etiology upon initial presentation vast, including ingestions, infections, metabolic derangements, stroke, or postictal changes. ${ }^{9}$ Electroencephalography (EEG) recordings can possibly reveal bitemporal or bioccipital slowing, though these changes, if present, resolve after the episode has resolved. ${ }^{10}$ Even for pediatric patients with common migraines, 36\% can have EEG abnormalities during a migraine, and $16 \%$ have abnormalities while headache free. ${ }^{11}$ Other atypical forms of migraine such as familial hemiplegic migraine or alternating hemiplegia can be seen in adolescents but tend to present initially in the earlier childhood year.

It is also possible to have nonorganic movement disorders associated with migraines. A study from Mayo Rochester ${ }^{12}$ in 2015 identified functional movement disorders in $4 \%$ of chronic migraine patients and $1 \%$ of episodic migraine patients with the most prominent movement being nonepileptic shaking spells.

\section{Syncope}

Syncope refers to a sudden loss of consciousness, often secondary to a reduction in cerebral perfusion. Syncope is commonly confused with seizure and presents a dilemma for the clinician, especially when the onset of the event was not witnessed. However, obtaining a careful and complete history often leads to clinical clues that can distinguish these two etiologies. Neurocardiogenic syncope is the most common type of syncope seen during childhood and adolescence, and is considered a reflex syncope with transient disturbances in autonomic control. ${ }^{13}$ This form of syncope can occur with the patient standing or sitting, and is often preceded by a prodrome of lightheadedness, nausea, and a gradual fading of binocular vision. Associated pallor and diaphoresis can also occur. Vasovagal syncope may be seen in adolescents as well and is usually precipitated by events such as pain or fear. ${ }^{14}$ Positive motor activity can be seen with various forms of syncope and should not automatically indicate a primary epileptic event. During prolonged periods of hypoperfusion versive eye movements, tonic stiffening and clonic jerks can occur. ${ }^{15}$ After the syncopal event, patients may feel tired for some time, though the return to baseline generally is quicker than that seen with epileptic events. ${ }^{13}$

Other forms of syncope are less common in adolescents but should be considered in the right clinical setting. Cardiogenic syncope can be associated with ominous signs such as syncope upon exertion and should promote a cardiac evaluation. ${ }^{6}$ This should not be confused, however, with postexertional postural hypotension that can occur and produce syncope and is less concerning. ${ }^{16}$ Hyperventilation that can occur during panic attacks can also lead to cerebral vasoconstriction and decreased cerebral blood flow resulting in syncope. $^{17}$

Testing for evaluation of syncope should be individualized for the patient and directed based on the historical clues. Electrocardiography can be useful for evaluation of cardiac arrhythmias, and orthostatic blood pressures can easily be obtained in patients with postural syncope. The use of routine EEG is questionable, given the low yield of information in between events. ${ }^{18}$ However, in patients with recurrent events, prolonged video EEG monitoring can be valuable when events are captured. During syncope, the EEG tends to demonstrate generalized slowing, and with severe events can reveal background suppression. ${ }^{19}$ Further testing, such as tilt testing or continuous Holter monitoring, should be determined based on individual cases.

\section{Movement Disorders}

Movement disorders are rarely confused with seizure activity, though some overlap in symptoms can occur. For example, in patients with tics or Tourette syndrome, atypical motor movements can be confused for simple focal seizures or myoclonic jerks. Tics are defined as rapid, recurrent motor movements or vocalizations that wax and wane over time. Tics tend to be motor or vocal and can be further divided into complex or simple depending on the complexity of tics. ${ }^{20}$ These movements affect up to $1 \%$ of the population and there is a male predominance. ${ }^{21,22}$ Although the mean age of onset is 5 years, the severity of the tics is often most prominent between 8 and 12 years of age. ${ }^{23}$ After these years, there tends to be an improvement in both intensity and frequency of the tics and some children, by the age of 18 years, no longer have any impairment from their tics. ${ }^{24}$ However, there remains a population of patients who continue to have severe and debilitating tics into adulthood. Diagnosis is based on clinical findings and certain clinical clues can help differentiate tics from other movement disorders and seizures. Patients with tics tend to report brief, rapid, nonrhythmical recurrent movements that can be temporarily suppressed, though this suppression leads to an uncomfortable sensation. This awareness of a tic being a self-directed conscious movement that is performed to satisfy an internal urge is expressed in the majority of patients with tics by the age of 12 years. ${ }^{25}$ Through careful obtainment of these historical clues, differentiation between tics and epileptic seizures is usually clear.

Paroxysmal dyskinesias represent another movement disorder that at times can be confused for seizure activity. Paroxysmal kinesigenic choreoathetosis or dyskinesia is characterized by brief episodes of choreoathetotic or dystonic movements, often initiated by a triggering event such as movement. ${ }^{26}$ The episodes can be unilateral or bilateral and typically are not associated with alteration in consciousness. These events do not represent an epileptic process and EEGs tend to be normal ${ }^{27}$; however, there have been reports of effective treatment with various antiepileptic medications. $^{26}$ Typical age at presentation is between 6 and 15 years. ${ }^{28}$ Paroxysmal dystonic choreoathetosis is a similar phenomenon but is not triggered by movements.

\section{Sleep Disorders}

Sleep disorders can be confused with epilepsy when the patient presents with paroxysmal recurrent events. Some epilepsy syndromes, such as nocturnal frontal lobe epilepsy, can include nocturnal seizures often with bizarre descriptions and should be considered in patients with stereotypical 
events during sleep. ${ }^{29}$ Common sleep phenomenon seen in younger children such as night terrors is not typically seen in the adolescent age group. The possibility of epilepsy may be raised with parasomnias such as sleep walking and talking, or with other sleep disorders such as narcolepsy and periodic limb movements.

Narcolepsy is a rapid eye movement sleep disorder characterized by excessive daytime sleepiness, cataplexy, sleep paralysis, and hypnagogic hallucinations; however, only a small percent of pediatric patients will report all of these symptoms. ${ }^{30}$ When the symptoms occur independently, these phenomena can be mistaken for epilepsy. For example, hypnagogic hallucinations seen in narcolepsy can be simple or complex and occur as the patient is falling asleep or upon awakening. However, the timing of these hallucinations as well as the patients insight into what is occurring suggests a diagnosis of narcolepsy. ${ }^{31}$ An association between narcolepsy and epilepsy has not been established and the two etiologies can be differentiated with the help of polysomnography and multiple sleep latency tests. ${ }^{30}$

Periodic limb movements of sleep are characterized by involuntary movements of the limbs occurring predominantly during non-rapid eye movement sleep. The majority of the cases will involve the legs only. ${ }^{32}$ Typical movements include dorsiflexion of the ankle with extension of the great toe and can be unilateral or bilateral. ${ }^{33}$ Clinical history and polysomnography should help differentiate these movements from epileptic events.

Sleep starts or myoclonus may also be confused with possible epileptic activity, though certain historical clues make the diagnosis of this benign phenomenon easy to detect. Also known as benign hypnic myoclonus, this movement involves sudden diffuse jerks that occur upon falling asleep. ${ }^{33}$ Patients at times describe a subjective sensation of falling when the jerk occurs. ${ }^{32}$ Unlike myoclonic epilepsy, these movements are restricted to sleep and occur as the patient transitions from wakefulness to sleep.

\section{Psychological Disorders}

The most common disorder to be mistaken for seizure activity in the adolescent is PNES. PNES refers to changes in perceived consciousness or behaviors that clinically are similar to epileptic seizures, but are not associated with an ictal epileptiform discharges. ${ }^{34}$ This is a common diagnosis encountered in epilepsy-monitoring units, given the clinical presentation of abnormal motor activity and alteration in apparent consciousness. The overall prevalence has been estimated at 2 to 33 per 100,000 with a female predominance. ${ }^{35-38}$ There is also an increasing incidence with progressing age in childhood. ${ }^{1}$ The true incidence in children is difficult to determine, but previous estimates have been between 1 and $9 \%{ }^{39}$

The correct diagnosis is often delayed, given the complexity of this disorder, and even the most trained epileptologist can mistake a nonepileptic spell for an epileptic seizure and vice versa. This is partially because there is no single characteristic that identifies a PNES. However, previous studies have identified common symptoms that can be suggestive of a psychogenic presentation. Characteristics such as asymmetrical thrashing movements, side-to-side head movements, pelvic thrusting, lack of a stereotypic pattern, waxing and waning of behaviors, sudden return to baseline followed by a prolonged generalized event, and rapid breathing at the end of the spell are clinical manifestations that can be more prominent in psychogenic seizures. ${ }^{40-44}$ In addition, PNES tend to last longer than epileptic seizures. A review of PNES in children by Szabó et $\mathrm{al}^{45}$ in 2012 found that PNES in children lasted on average 186 seconds longer than epileptic seizures in children. Activation procedures can also be used to induce typical events in patients with PNES. ${ }^{46}$

Although the above are possible characteristics of psychogenic seizures, there can be an overlap in symptoms between epileptic and nonepileptic events, often requiring video EEG monitoring to correctly differentiate between the two. Previous studies have shown that even experienced epileptologists can incorrectly distinguish between epileptic and psychogenic seizures from video recordings alone in up to 30\% of cases. ${ }^{47}$ The most common type of epileptic seizure to be mistaken for a psychogenic seizure is a frontal lobe seizure that can often include bizarre presentations. ${ }^{48}$

It is important to recognize these PNES symptoms and make the correct diagnosis, as an incorrect diagnosis of epilepsy can lead to treatment with unnecessary antiepileptic medication, which will also be ineffective. In addition, the diagnosis of PNES requires a different approach to treatment, including cognitive behavioral psychotherapy, stress reduction, and reassurance. ${ }^{49}$ The communication of the diagnosis to the patient and the parents is also of vital importance with emphasis being placed that the child is not faking these events. ${ }^{50}$ Typically, in children and adolescents, PNES are thought to be a manifestation of conversion disorder ${ }^{51}$ and the diagnosis should be conveyed positively without blame placed on the patient. ${ }^{52}$ Adolescence represents an awkward period of time when a child morphs into an adult both physically and psychologically. This period of change is accompanied by many psychosocial stressors such as self-image, peer pressure, sexual changes and encounters, relationships with others, and many other problems that can lead to confusion and unresolved psychological conflicts that may manifest as physical symptoms that may include PNES. A common pattern is that PNES attract much attention from family members and friends, and often result in ambulance rides, emergency department visits, medical tests, and hospitalization, which commonly serve to convince the afflicted patient that they are indeed very ill. These all commonly result in a pattern of recurring events with a self-perpetuating, increasing frequency of occurrence. Recording the typical events with video EEG is the gold standard for making the correct diagnosis and providing appropriate intervention. It is extremely important to convince the patient and family that the spells are not epileptic seizures as confirmed by the absence of epileptic activity on the EEG. This is the first step in intervention. It is next important to obtain psychological consultation to explore the potential for underlying psychological conflicts that need to be dealt 
with appropriately. Failure to complete this final step may result in persistence of PNES versus the development of other somatized complaints or disabilities. With early intervention, it appears that children and adolescents have a significantly better prognosis compared with adults with up to $81 \%$ free of PNES at 3-year follow-up. ${ }^{53}$ Of note, it should be recognized that patients can have both epileptic and psychogenic events, therefore requiring a complex regimen to treat the individual etiologies. These children tend to have a less favorable outcome. ${ }^{52}$

In conclusion, paroxysmal nonepileptic spells continue to be a challenge and early identification of the correct diagnosis can minimize unnecessary investigations and treatments. These spells can have an organic or psychogenic basis and because of overlapping neurologic symptoms with epileptic seizures, diagnosis can be delayed for many years. It is important for the health care provider to be familiar with common nonepileptic spells seen in adolescents as described earlier to avoid unnecessary treatment with antiepileptic medications and to instead formulate appropriate treatment for these patients.

\section{References}

1 Kotagal P, Costa M, Wyllie E, Wolgamuth B. Paroxysmal nonepileptic events in children and adolescents. Pediatrics 2002; 110(4):e46

2 Tarantino S, Capuano A, Torriero R, et al. Migraine equivalents as part of migraine syndrome in childhood. Pediatr Neurol 2014; 51(5):645-649

3 Andermann F, Zifkin B. The benign occipital epilepsies of childhood: an overview of the idiopathic syndromes and of the relationship to migraine. Epilepsia 1998;39(Suppl 4): S9-S23

4 Cutrer FM, Huerter K. Migraine aura. Neurologist 2007;13(3): 118-125

5 Panayiotopoulos CP. Visual phenomena and headache in occipital epilepsy: a review, a systematic study and differentiation from migraine. Epileptic Disord 1999;1(4):205-216

6 Obeid M, Mikati MA. Expanding spectrum of paroxysmal events in children: potential mimickers of epilepsy. Pediatr Neurol 2007; 37(5):309-316

7 Amit R. Acute confusional state in childhood. Childs Nerv Syst 1988;4(5):255-258

8 Sheth RD, Riggs JE, Bodensteiner JB. Acute confusional migraine: variant of transient global amnesia. Pediatr Neurol 1995;12(2): 129-131

9 Shaabat A. Confusional migraine in childhood. Pediatr Neurol 1996;15(1):23-25

10 Pietrini V, Terzano MG, D’Andrea G, Parrino L, Cananzi AR, FerroMilone F. Acute confusional migraine: clinical and electroencephalographic aspects. Cephalalgia 1987;7(1):29-37

11 Ozkan M, Teber ST, Deda G. Electroencephalogram variations in pediatric migraines and tension-type headaches. Pediatr Neurol 2012;46(3):154-157

12 Youssef PE, Mack KJ. Abnormal movements in children with migraine. J Child Neurol 2015;30(3):285-288

13 McLeod KA. Syncope in childhood. Arch Dis Child 2003;88(4): 350-353

14 Brignole M, Alboni P, Benditt DG, et al; Task Force on Syncope, European Society of Cardiology. Guidelines on management (diagnosis and treatment) of syncope-update 2004. Europace 2004; 6(6):467-537
15 Lempert T, Bauer M, Schmidt D. Syncope: a videometric analysis of 56 episodes of transient cerebral hypoxia. Ann Neurol 1994;36(2): 233-237

16 Tretter JT, Kavey RE. Distinguishing cardiac syncope from vasovagal syncope in a referral population. J Pediatr 2013;163(6): 1618-1623.e1

17 David JE, Yale SH, Vidaillet HJ. Hyperventilation-induced syncope: no need to panic. Clin Med Res 2003;1(2):137-139

18 Pires LA, Ganji JR, Jarandila R, Steele R. Diagnostic patterns and temporal trends in the evaluation of adult patients hospitalized with syncope. Arch Intern Med 2001;161(15):1889-1895

19 Brenner RP. Electroencephalography in syncope. J Clin Neurophysiol 1997;14(3):197-209

20 Leckman JF, King RA, Cohen DJ. Tics and tic disorders. In: Leckman JF, Cohen DJ, eds. Tourette's Syndrome-Tics, Obsessions, Compulsions: Developmental Psychopathology and Clinical Care. New York, NY: Wiley; 1999:23-42

21 Stern JS, Burza S, Robertson MM. Gilles de la Tourette's syndrome and its impact in the UK. Postgrad Med J 2005;81(951):12-19

22 Robertson MM. The prevalence and epidemiology of Gilles de la Tourette syndrome. Part 1: the epidemiological and prevalence studies. J Psychosom Res 2008;65(5):461-472

23 Leckman JF, Zhang H, Vitale A, et al. Course of tic severity in Tourette syndrome: the first two decades. Pediatrics 1998;102(1, Pt 1):14-19

24 Pappert EJ, Goetz CG, Louis ED, Blasucci L, Leurgans S. Objective assessments of longitudinal outcome in Gilles de la Tourette's syndrome. Neurology 2003;61(7):936-940

25 Leckman JF. Phenomenology of tics and natural history of tic disorders. Brain Dev 2003;25(Suppl 1):S24-S28

26 Lotze T, Jankovic J. Paroxysmal kinesigenic dyskinesias. Semin Pediatr Neurol 2003;10(1):68-79

27 Kang H, Hu Q, Liu X, Xu F, Chen L, Zhu S. Clinical characteristics of paroxysmal kinesigenic choreoathetosis: diagnosis, treatment and prognosis. J Huazhong Univ Sci Technolog Med Sci 2009;29(1): 118-121

28 Bruno MK, Hallett M, Gwinn-Hardy K, et al. Clinical evaluation of idiopathic paroxysmal kinesigenic dyskinesia: new diagnostic criteria. Neurology 2004;63(12):2280-2287

29 Malow BA. Sleep and epilepsy. Neurol Clin 2005;23(4):1127-1147

30 Nevsimalova $S$. The diagnosis and treatment of pediatric narcolepsy. Curr Neurol Neurosci Rep 2014;14(8):469

31 Ohayon MM. Prevalence of hallucinations and their pathological associations in the general population. Psychiatry Res 2000;97(23):153-164

32 Walters AS. Clinical identification of the simple sleep-related movement disorders. Chest 2007;131(4):1260-1266

33 Derry CP, Duncan JS, Berkovic SF. Paroxysmal motor disorders of sleep: the clinical spectrum and differentiation from epilepsy. Epilepsia 2006;47(11):1775-1791

34 Metrick ME, Ritter FJ, Gates JR, Jacobs MP, Skare SS, Loewenson RB. Nonepileptic events in childhood. Epilepsia 1991;32(3):322-328

35 Ramsay RE, Cohen A, Brown MC. Coexisting epilepsy and nonepileptic seizures. In: Rowan AJ, Gates JR, eds. Non-epileptic Seizures. Boston, MA: Butterworth-Heinemann; 1993:47-54

36 Benbadis SR, Allen Hauser W. An estimate of the prevalence of psychogenic non-epileptic seizures. Seizure 2000;9(4):280-281

37 Duncan R, Razvi S, Mulhern S. Newly presenting psychogenic nonepileptic seizures: incidence, population characteristics, and early outcome from a prospective audit of a first seizure clinic. Epilepsy Behav 2011;20(2):308-311

38 Lesser RP. Psychogenic seizures. In: Pedley TA, Meldrum BS, eds. Recent Advances in Epilepsy. New York: Churchill-Livingstone; 1985:273-296

39 Reilly C, Menlove L, Fenton V, Das KB. Psychogenic nonepileptic seizures in children: a review. Epilepsia 2013;54(10):1715-1724

40 Boon PA, Williamson PD. The diagnosis of pseudoseizures. Clin Neurol Neurosurg 1993;95(1):1-8 
41 Walczak TS, Bogolioubov A. Weeping during psychogenic nonepileptic seizures. Epilepsia 1996;37(2):208-210

42 Chabolla DR, Shih JJ. Postictal behaviors associated with psychogenic nonepileptic seizures. Epilepsy Behav 2006;9(2):307-311

43 Sen A, Scott C, Sisodiya SM. Stertorous breathing is a reliably identified sign that helps in the differentiation of epileptic from psychogenic non-epileptic convulsions: an audit. Epilepsy Res 2007;77(1):62-64

44 Rosemergy I, Frith R, Herath S, Walker E. Use of postictal respiratory pattern to discriminate between convulsive psychogenic nonepileptic seizures and generalized tonic-clonic seizures. Epilepsy Behav 2013;27(1):81-84

45 Szabó L, Siegler Z, Zubek L, et al. A detailed semiologic analysis of childhood psychogenic nonepileptic seizures. Epilepsia 2012; 53(3):565-570

46 Benbadis SR, Johnson K, Anthony K, et al. Induction of psychogenic nonepileptic seizures without placebo. Neurology 2000;55(12): 1904-1905
47 King DW, Gallagher BB, Murvin AJ, et al. Pseudoseizures: diagnostic evaluation. Neurology 1982;32(1):18-23

48 Saygi S, Katz A, Marks DA, Spencer SS. Frontal lobe partial seizures and psychogenic seizures: comparison of clinical and ictal characteristics. Neurology 1992;42(7):1274-1277

49 LaFrance WC Jr, Reuber M, Goldstein LH. Management of psychogenic nonepileptic seizures. Epilepsia 2013;54(Suppl 1):53-67

50 Plioplys S, Asato MR, Bursch B, Salpekar JA, Shaw R, Caplan R. Multidisciplinary management of pediatric nonepileptic seizures. J Am Acad Child Adolesc Psychiatry 2007;46(11):1491-1495

51 Reuber M. Psychogenic nonepileptic seizures: answers and questions. Epilepsy Behav 2008;12(4):622-635

52 Irwin K, Edwards M, Robinson R. Psychogenic non-epileptic seizures: management and prognosis. Arch Dis Child 2000; 82(6):474-478

53 Wyllie E, Friedman D, Lüders H, Morris H, Rothner D, Turnbull J. Outcome of psychogenic seizures in children and adolescents compared with adults. Neurology 1991;41(5):742-744 